\title{
Evaluating multispecies landscape connectivity in a threatened tropical mammal community
}

\author{
Jedediah F. Brodie, ${ }^{*}$ Anthony J. Giordano, $\nmid$ Brett Dickson, $\neq \varnothing$ Mark Hebblewhite, ${ }^{* *}$ \\ Henry Bernard, $\uparrow \dagger$ Jayasilan Mohd-Azlan, $\neq \ddagger$ Jesse Anderson, $\neq$ and Laurentius Ambu $₫ ₫$ \\ ${ }^{*}$ Departments of Zoology \& Botany, Biodiversity Research Centre, University of British Columbia, 3529-6270 University Blvd, \\ Vancouver, British Columbia V6T 1Z4, Canada, email brodie@biodiversity.ubc.ca \\ †Department of Natural Resources Management, Box 42125, Goddard Hall, Texas Tech University, Lubbock, TX 79409, U.S.A. \\ ¥Conservation Science Partners, Inc., 11050 Pioneer Trail, Suite 202, Truckee, CA 96161, U.S.A. \\ §Lab of Landscape Ecology and Conservation Biology, Landscape Conservation Initiative, Northern Arizona University, Box 5694 , \\ Flagstaff, AZ 86011, U.S.A. \\ ${ }^{* *}$ Wildlife Biology Program, Department of Ecosystem and Conservation Science, University of Montana, 32 Campus Drive, Missoula, \\ MT 59812, U.S.A. \\ ††Institute for Tropical Biology and Conservation, Universiti Malaysia Sabah, 88999 Kota Kinabalu, Sabah, Malaysia \\ $\ddagger \ddagger$ Department of Zoology, Faculty of Resource Science and Technology, Universiti Malaysia Sarawak, 94300 Kota Samarahan, Sarawak, \\ Malaysia \\ \§Sabah Wildlife Department, Ibu Pejabat Tingkat 5, Blok B Wisma Muis, 88100 Kota Kinabalu, Sabah, Malaysia
}

\begin{abstract}
Habitat corridors are important tools for maintaining connectivity in increasingly fragmented landscapes, but generally they have been considered in single-species approaches. Corridors intended to facilitate the movement of multiple species could increase persistence of entire communities, but at the likely cost of being less efficient for any given species than a corridor intended specifically for that species. There have been few tests of the trade-offs between single-and multispecies corridor approaches. We assessed single-species and multispecies habitat corridors for 5 threatened mammal species in tropical forests of Borneo. We generated maps of the cost of movement across the landscape for each species based on the species' local abundance as estimated through hierarchical modeling of camera-trap data with biophysical and anthropogenic covariates. Elevation influenced local abundance of banded civets (Hemigalus derbyanus) and sun bears (Helarctos malayanus). Increased road density was associated with lower local abundance of Sunda clouded leopards (Neofelis diardi) and higher local abundance of sambar deer (Rusa unicolor). Pig-tailed macaque (Macaca nemestrina) local abundance was lower in recently logged areas. An all-species-combined connectivity scenario with least-cost paths and $1 \mathrm{~km}$ buffers generated total movement costs that were $27 \%$ and $23 \%$ bigher for banded civets and clouded leopards, respectively, than the connectivity scenarios for those species individually. A carnivore multispecies connectivity scenario, however, increased movement cost by $2 \%$ for banded civets and clouded leopards. Likewise, an herbivore multispecies scenario provided more effective connectivity than the all-species-combined scenario for sambar and macaques. We suggest that multispecies habitat connectivity plans be tailored to groups of ecologically similar, disturbance-sensitive species to maximize their effectiveness.
\end{abstract}

Keywords: animal movement, Borneo, dispersal, fragmentation, habitat corridor, Heart of Borneo, logging, multispecies conservation

Evaluación de la Conectividad de Terrenos Multiespecie en una Comunidad Tropical de Mamíferos

Resumen: Los corredores de bábitats son berramientas importantes para mantener la conectividad en terrenos cada vez más fragmentados, pero generalmente se baconsiderado que solo son usados en estrategias para especies individuales. Los corredores que pretenden facilitar el movimiento de especies múltiples podrían aumentar la persistencia de comunidades enteras con el costo probable de ser menos eficientes para cualquier

Paper submitted November 25, 2013; revised manuscript accepted April 3, 2014. 